\title{
Long-term results of mitral valve reconstruction for regurgitation of the myxomatous mitral valve
}

The myxomatous, degenerated, prolapsed or "floppy" mitral valve is the most common cause of mitral regurgitation in North America. Mitral valve reconstruction for mitral regurgitation was carried out in 219 consecutive patients with a myxomatous mitral valve from 1984 to 1993 . Of the 139 men and 80 women, 23 to 84 years of age (mean 63 years), $36 \%$ of patients were 70 years of age or older, $77 \%$ were in New York Heart Association functional class III or IV, and $29 \%$ had coronary artery disease necessitating coronary bypass. The most common operation was posterior leaflet resection (161 patients [73\% ]). The anterior leaflet was resected in 14 patients, and both the anterior and posterior leaflets were resected in 15 patients. A variety of other techniques were used, including commissuroplasty and use of annuloplasty rings. A flexible Duran ring was used in 111 patients $(51 \%$ ), a Carpentier-Edwards ring in 44 patients $(20 \%)$, and no ring was used in 64 patients $(29 \%)$. Five operative deaths occurred $(2.3 \%)$; four of the five deaths occurred in patients 70 years of age or older $(5.1 \%)$; and one in 141 patients $(0.7 \%)$ was younger than 70 years of age. In the late postoperative period (mean follow-up 2 years), $90 \%$ of patients had no symptoms, two had endocarditis, and seven patients had thromboemboli (transient in four, permanent in three). Structural valve degeneration requiring reoperation occurred late in 12 patients; eight were in posterior leaflet resection and two in anterior or anterior and posterior; six of 12 had no annuloplasty ring. The incidence of structural valve degeneration was less than $5 \%$ from 1990 to 1993 . No systolic anterior motion of the mitral valve was seen with postoperative echocardiography before discharge. Actuarial analysis at 5 years for overall survival was $86 \% \pm \mathbf{5} \%$, freedom from infectious valve degeneration $97 \% \pm \mathbf{2} \%$, and freedom from thromboembolism $94 \% \pm 3 \%$. Freedom from structural valve degeneration overall was $83 \% \pm 4 \%$, with a flexible ring it was $89 \% \pm 6 \%$, with a rigid ring it was $88 \% \pm 6 \%$, and with no ring it was $67 \% \pm 12 \%(p=0.03)$. Mitral valve reconstruction for complicated myxomatous disease of the mitral valve, regardless of leaflet involvement, is feasible and offers excellent early and late results. ( $J$ THORAC CaRDIOvaSC Surg 1994;107:143-51)

Lawrence H. Cohn, MD, Gregory S. Couper, MD (by invitation), Sary F. Aranki, MD

(by invitation), Robert J. Rizzo, MD (by invitation), Nancy M. Kinchla, BS (by invitation), and John J. Collins, Jr., MD, Boston, Mass.

$\mathrm{M}$ ducing the so-called floppy mitral valve is the most common abnormality of human heart valves and is a major cause of mitral regurgitation in North America. ${ }^{1-3}$ The

From the Division of Cardiac Surgery, Brigham and Women's Hospital, and the Department of Surgery, Harvard Medical School, Boston, Mass.

Read at the Seventy-third Annual Meeting of The American Association for Thoracic Surgery, Chicago, Ill., April 25-28, 1993.

Address for reprints: Lawrence $\mathrm{H}$. Cohn, MD, Chief, Division of Cardiac Surgery, Brigham and Women's Hospital, 75 Francis St., Boston, MA 02115.

Copyright ${ }^{\circledR} 1994$ by Mosby-Year Book, Inc.

$0022-5223 / 94 \$ 1.00+.10 \quad 12 / 6 / 50820$ leaflets and chordae tendineae stretch as a result of deposition of myxomatous material in the valve leaflets and chordae resulting in mitral valve prolapse, especially of the posterior leaflet. ${ }^{4}$ Mitral valve prolapse is very common in women 20 to 30 years old, but increases in men with age, often requiring operation for severe mitral regurgitation. ${ }^{1-3}$ This report summarizes experience at the Brigham and Women's Hospital, from 1981 to 1993, on mitral valve reparative procedures in patients with isolated mitral regurgitation from myxomatous degeneration.

\section{Patients and methods}

All patients undergoing mitral valve repair for mitral regurgitation as a result of myxomatous degeneration from January 
Table I. Mitral repair of floppy valve: demographics at Brigham and Women's Hospital 1981-93

\begin{tabular}{lc}
\hline No. of patients & 219 \\
M/F & $139: 80$ \\
Age $(y r)$ & $23-84($ mean 63$)$ \\
Age $\geq 70$ & $78(36 \%)$ \\
Coronary artery disease & $63(29 \%)$ \\
Atrial fibrillation & $82(38 \%)$ \\
NYHA functional classification & \\
I, II & $50(23 \%)$ \\
III, IV & $169(77 \%)$ \\
\hline
\end{tabular}

Table II. Mitral repair of floppy valve: demographics at Brigham and Women's Hospital 1981-93

\begin{tabular}{ccc}
\hline & \multicolumn{2}{c}{ No. of patients } \\
\cline { 2 - 3 } NYHA functional classification & Preoperative & Postoperative \\
\hline I & 5 & 149 \\
II & 45 & 31 \\
III & 136 & 3 \\
IV & 33 & 0 \\
\hline
\end{tabular}

1981 to March 1993 were reviewed. A total of 360 patients overall with this diagnosis were treated at Brigham and Women's Hospital, 141 with valve replacement. There were 219 patients with mitral valve repair, all of whom had severe mitral regurgitation as determined with preoperative Doppler echocardiography or left ventriculography. Demographics of this patient group are found in Table I. In this series, patients were excluded if they had other major valve lesions, such as aortic valve disease or major tricuspid valve regurgitation. There was a predominance of women, patients with coexistent coronary artery disease, and patients 70 years of age or older. In addition, about one third of the patients had chronic atrial fibrillation. New York Heart Association (NYHA) functional classification is shown in Table II. Patients in functional classification I and II had minimal symptoms and underwent operation either because of marked increase in left ventricular end-diastolic and end-systolic dimensions, as determined by serial echocardiographic examinations, or, for a small number of patients, intermittent atrial fibrillation. The left ventricular ejection fraction was calculated in most, but not all patients, by left ventriculography or echocardiography.

Operative techniques. All operations were performed with the use of cardiopulmonary bypass, cold hyperkalemic cardioplegic solution (blood or crystalloid), and a single aortic crossclamp. If concomitant coronary artery bypass grafting was done, the distal coronary artery anastomoses were done before valve repair and perfusion with cardioplegic solution through the distal grafts, and the proximal coronary anastomosis were done after closure of the left atrium. Table III summarizes the operative techniques used in this diverse group of 219 patients according to leaflet resections, adjunctive procedures such as commissuroplasty and chordoplasty, and the type of annuloplasty treatment (ring or no ring).

The reparative techniques were performed with emphasis on principles originally described by Carpentier ${ }^{5}$ and Duran ${ }^{6}$ with
Table III. Mitral repair of floppy valve: operative technique

\begin{tabular}{lcc}
\hline & No. of patients & $\begin{array}{c}\text { Structural valve } \\
\text { degeneration }\end{array}$ \\
\hline Posterior leaflet resection & 38 & 8 \\
$\quad$ Only & 123 & 6 \\
$\quad$ Ring plus other & 2 & \\
Anterior leaflet resection & 12 & 3 \\
$\quad$ Only & 15 & \\
$\quad$ Ring plus other & & 0 \\
Anterior/posterior leaflet resection & \\
$\quad$ Ring & 9 & 2 \\
No leaflet resection & 20 & 2 \\
$\quad$ Ring only & 219 & 21 \\
$\quad$ Ring plus other & & \\
Total &
\end{tabular}

Table IV. Mitral repair of floppy valve: mortality

\begin{tabular}{|c|c|c|}
\hline \multicolumn{3}{|l|}{ Operative mortality } \\
\hline Overall & $5 / 219(2.3 \%)$ & \\
\hline$<70 \mathrm{yr}$ & $1 / 141(0.7 \%)$ & \\
\hline$\geq 70 \mathrm{yr}$ & $4 / 78(5.1 \%)$ & $p=\mathrm{NS}$ \\
\hline With CABG & $1 / 63(1.6 \%)$ & \\
\hline Without CABG & $4 / 156(2.6 \%)$ & $p=\mathrm{NS}$ \\
\hline \multicolumn{3}{|l|}{ Late mortality } \\
\hline Noncardiac & 5 & \\
\hline Suicide & 2 & \\
\hline Brain stem & 1 & \\
\hline Hepatic failure & 1 & \\
\hline Septicemia & 1 & \\
\hline Cardiac & 6 & \\
\hline $\mathrm{CHF}$ & 3 & \\
\hline Arrhythmia & 2 & \\
\hline MI & 1 & \\
\hline Total & $11 / 219(5 \%)$ & \\
\hline
\end{tabular}

NS, Not significant; $C A B G$, coronary artery bypass graft; $C H F$, chronic heart failure; $M I$, mitral insufficiency.

certain modifications. ${ }^{7}$ The most common operation was resection of the prolapsed midscallop of the posterior leaflet and placement of a flexible annuloplasty ring. Correction of the anterior leaflet by limited resection, chordal transfer from posterior to anterior leaflet, and, in these cases, replacement of anterior leaflet chordae by polytetrafiuoroethylene sutures ${ }^{8 *}$ were also used. Commissuroplasty was used primarily for posterior commissural prolapse. In two patients extensive posterior leaflet calcification was removed in its entirety by the technique of Carpentier'; the reattachment of the leaflet to the anulus and the repair of the posterior leaflet were carried out as usual. Annuloplasty techniques varied: no annuloplasty ring was used in 64 patients $(29 \%)$, the Carpentier-Edwards ring (Baxter Healthcare Corp., Edwards Division, Santa Ana, Calif.) was used in 44 patients (20\%), and the Duran ring (Medtronic, Inc., Minneapolis, Minn.) was used in 111 patients $(51 \%)$.

*Gore-Tex suture, registered trademark of W. L. Gore \& Associates, Inc., Newark, Del. 


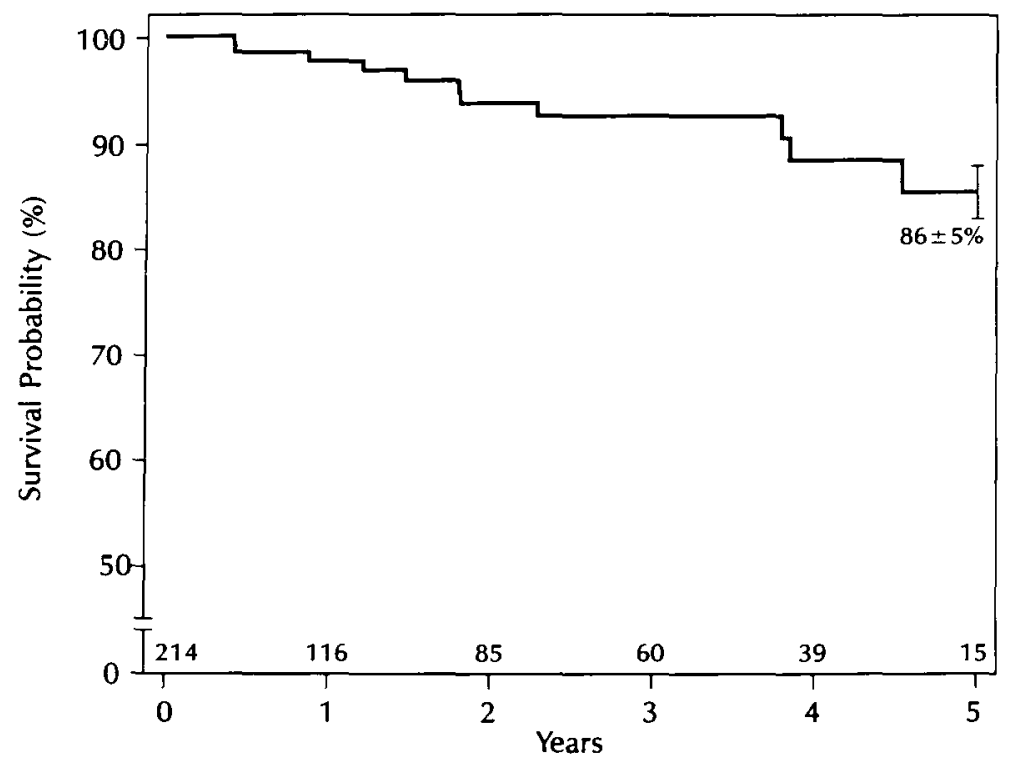

Fig. 1. Actuarial survival curves showing overall mortality.

Intraoperative transesophageal Doppler echocardiography has been routinely used in the past 3 years, and every patient had a postoperative Doppler echocardiogram before leaving the hospital at 4 to 7 days. Patients in atrial fibrillation underwent anticoagulation therapy at approximately $50 \%$ above control levels before leaving the hospital. Patients in sinus rhythm, regardless of the type of annuloplasty treatment, were given 320 mg of aspirin a day and had no other anticoagulation regimen.

Follow-up. All patients were contacted and followed up by the clinical research group of the Division of Cardiac Surgery beginning in the winter of 1993. Operative death was defined as any death occurring within 30 days or during the initial hospitalization. Late deaths, thromboembolic complications, infectious valve dysfunction, structural valve degeneration, and reoperations were reviewed, and Kaplan-Meier survival curves were constructed. Univariate analyses included done with $\chi^{2}$ or Fisher's exact test. Early and late survival among groups were compared by the log-rank test.

Combinations of variables, including age, concomitant coronary bypass, functional class, and rhythm, were tested simultaneously by multivariate analysis for survival. Similarly, the variables of anterior leaflet resection and presence or absence of annuloplasty ring were evaluated for structural valve degeneration with the Cox proportional-hazards model. ${ }^{10}$

\section{Results}

There were five operative deaths in the 219 (2.3\%) patients who underwent operation on for mitral regurgitation with reparative techniques. All deaths were due to noncardiac causes: respiratory failure $(n=2)$, ischemic bowel $(n=1)$, aortic dissection $(n=1)$, and anticoagulant hemorrhage $(n=1)$. Four of the five deaths occurred in patients who were over the age of 70 ; only one death occurred in the 141 patients under the age of 70 undergoing mitral valve repair (Table IV). Patients who had
Table V. Mitral repair of floppy valve: 5-year freedom from morbidity

\begin{tabular}{ll}
\hline TE & $94 \% \pm 3 \%$ \\
IVD & $97 \% \pm 2 \%$ \\
SVD & $83 \% \pm 4 \%$ \\
REOP & $83 \% \pm 4 \%$ \\
A/C Hem & $98 \% \pm 1 \%$ \\
Total & $74 \% \pm 5 \%$ \\
\hline
\end{tabular}

$T E$, Thromboembolism; $I V D$, infectious valve degeneration; $S V D$, structural valve degeneration; $R E O P$, reoperation: $A / C H e m$, anticoagulant-related hemorrhage.

concomitant coronary bypass did not appear to have a significantly increased operative risk.

Patients were followed up for 1 to 10 years (mean 2 years), and no patient was lost to follow-up. There were 11 late deaths, six cardiac and five noncardiac (Table IV). Those who were in the elderly age group had a higher (but not significantly) rate of late cardiac mortality. Fig. 1 shows the overall survival, with a 5-year survival of $84 \% \pm 7 \%$ of patients over 70 years of age and $87 \%$ to $5 \%$ of patients younger than 70 years of age.

Thromboembolic complications. Seven patients had a thromboembolic complication in the late postoperative period, four of which were transient and classified as transient ischemic attacks and three of which were permanent with minimal sequelae. In Fig. 2, $A$, the actuarial overall probability of freedom from thromboembolic events at 5 years was $94 \%$ to $3 \%$. Patients were classified in the postoperative period according to rhythm; 71 were in chronic atrial fibrillation, and 142 were in sinus rhythm. These two patient groups were compared for thromboem- 

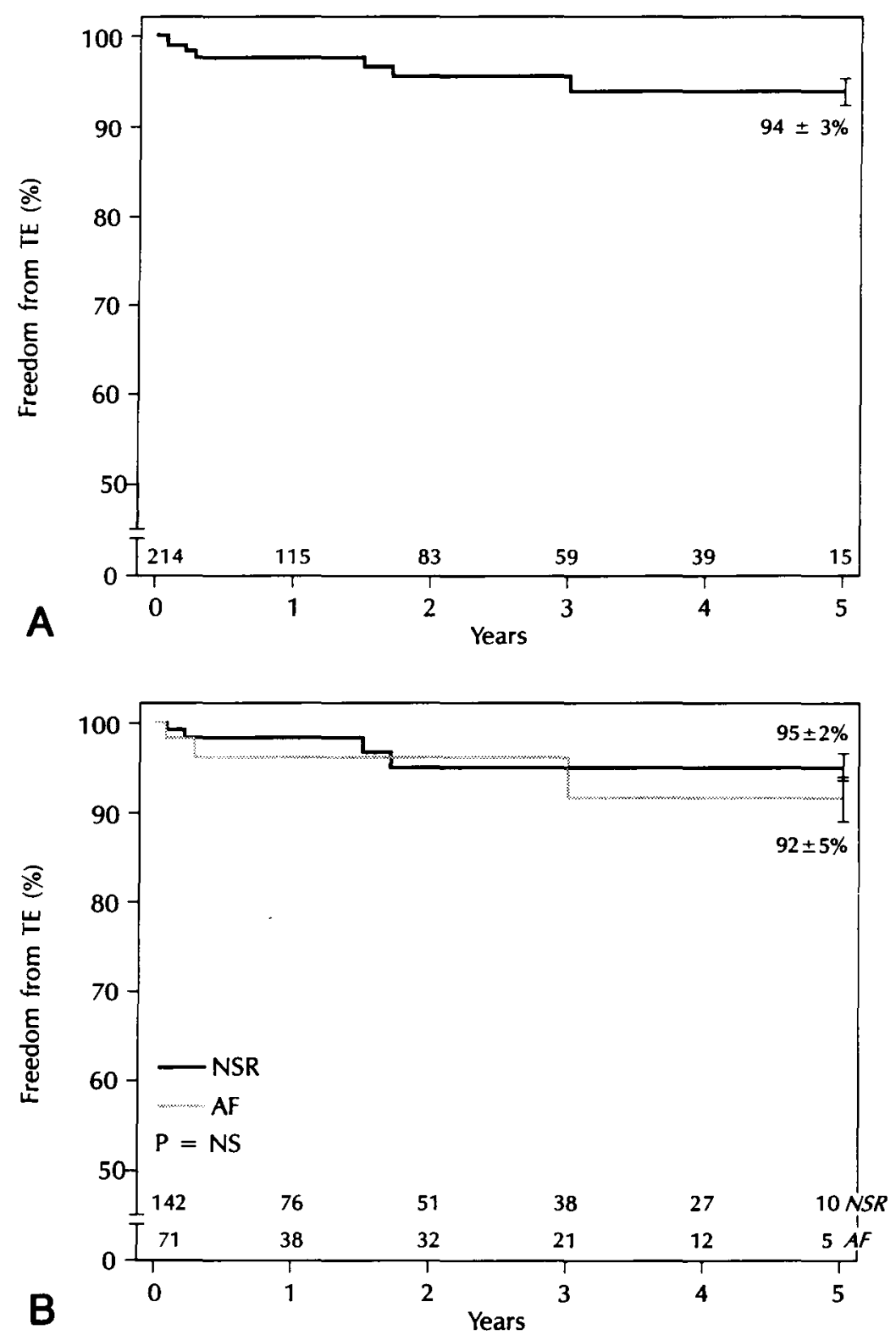

Fig. 2. Actuarial curve for freedom from thromboembolism (A), and actuarial curves for thromboembolic risk, separated by postop rhythm, and atrial fibrillation or sinus rhythm (B).

bolic events; the prevalence was higher in those with atrial fibrillation, but it was not statistically significant (Fig. 2, B). Anticoagulant hemorrhage was seen in three patients. Patients who died during the operation and one patient in whom rhythm data was not documented are not included in this analysis.

Infectious valve degeneration. Infectious valve dysfunction occurred in two instances in the late postoperative period with a probability of freedom from infectious valve degeneration of $97 \% \pm 2 \%$ at 5 years (Table V).
Postoperative functional classification. The postoperative functional classification dramatically improved, with 180 patients in functional classifications I and II and only three patients in functional classifications III and IV (Table II). Operative deaths, postoperative deaths, and reoperations were excluded from functional class analysis; thus, data on only 183 patients was included in this analysis.

Structural valve degeneration and reoperation. Systolic anterior motion of the anterior leaflet of the mitral 

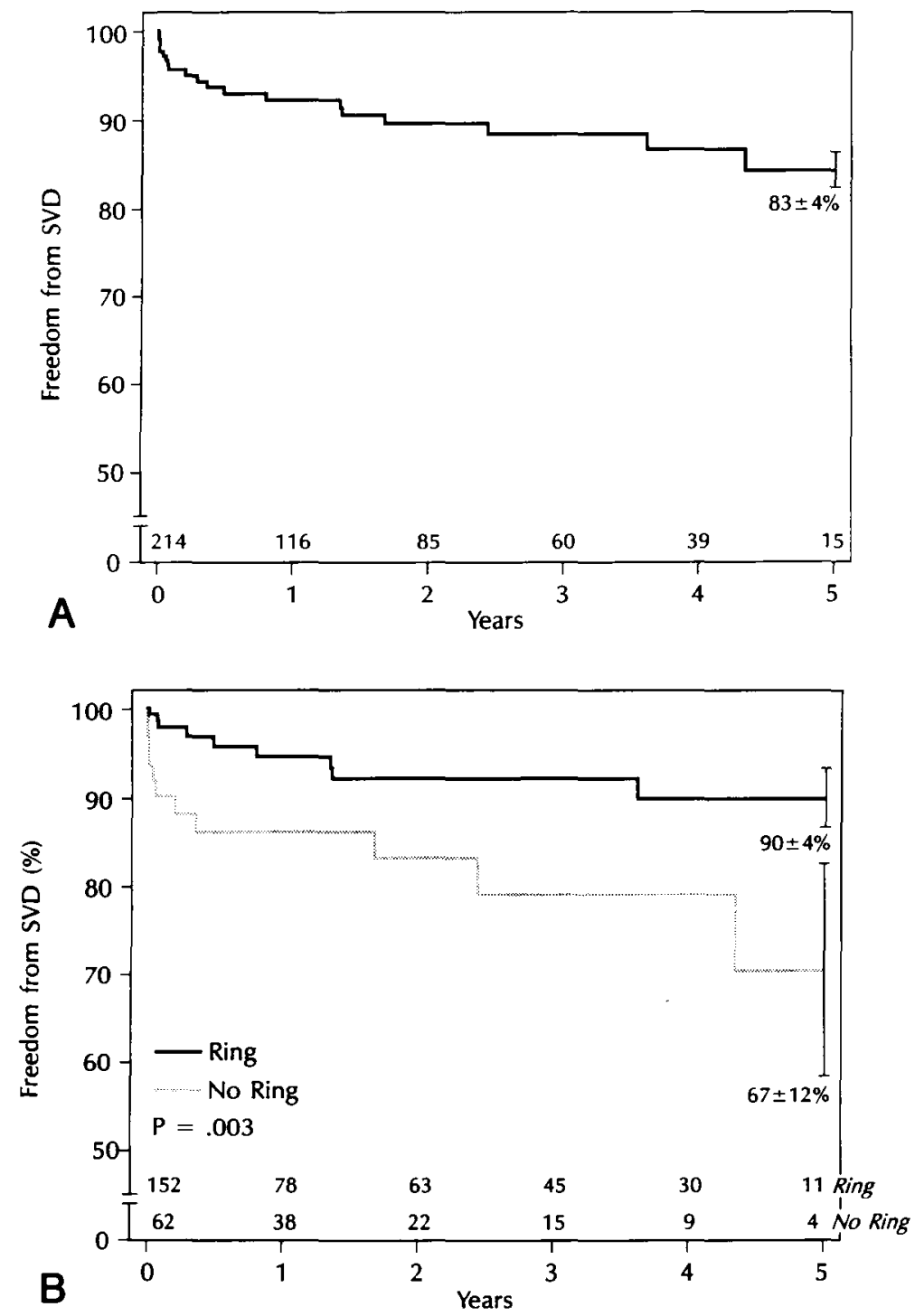

Fig. 3. Actuarial curve for overall structural valve degeneration(A), and actuarial curves for SVD comparing repairs with an annuloplasty ring versus no ring (B).

valve was not noted in any patient in the postoperative period. Of the 219 patients, $20(9 \%)$ required a reoperation for structural valve degeneration. Eight of the reoperations were early failures (within 1 week), and 12 were late failures. The majority of these patients underwent operation in the first years of this series, with 15 of the 20 $(15 / 117,13 \%)$ undergoing reoperation from 1981 to 1989 , whereas only five patients required reoperation from 1990 to $1993(5 / 102,5 \%)$. Fig. 3, $A$ shows the overall freedom from structural valve degeneration at 5 years at $83 \% \pm 4 \%$. The time from operation to the appearance of structural valve degeneration was 1 to 10 years with a median of 1.3 years. At reoperation, replace- ment was carried out in 18 patients and re-repair in two patients. In Table III, there is an analysis of the structural valve degeneration by procedure. Posterior leaflet resection with no annuloplasty ring had the highest prevalence of dysfunction. Patients who had generalized prolapse without localized findings also had a relatively high prevalence of structural valve degeneration. In patients who had both anterior and posterior leaflet resections with annuloplasty ring and commissuroplasties, no long-term structural valve degeneration was found. Kaplan-Meier survival curves were calculated on the basis of whether a ring annuloplasty was performed (Fig. 3,B). No statistical difference was found between the Duran (Medtronic) 


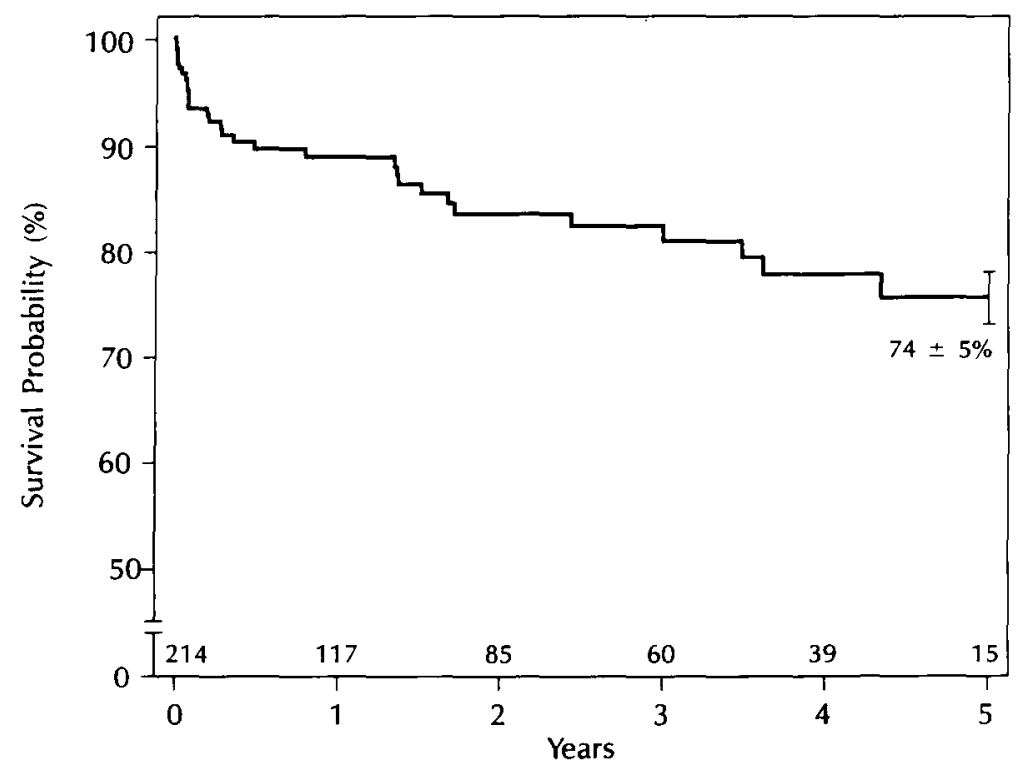

Fig. 4. Actuarial curve of freedom from all morbidity.

or Carpentier-Edwards ring (Baxter), but a significant statistical difference was noted between those patients who had an annuloplasty ring and those with no annuloplasty ring in the course of their mitral valve repair $(p=0.003)$. In the multivariate analysis, the only variable found to be associated with an increased risk of structural valve degeneration was the absence of an annuloplasty ring.

The probability of freedom from all morbidity at 5 years was $74 \% \pm 5 \%$ (Fig. 4).

\section{Discussion}

Mitral valve regurgitation caused by myxomatous degeneration can be repaired in the majority of cases. ${ }^{4-9}$ This study, like others that have been recently reported, ${ }^{11,12}$ has indicated that even in complex repairs involving both the anterior and the posterior leaflet, there can be a reasonable expectation of a competent valve with long-lasting durability; these findings confirm the pioneering work of both Carpentier and Duran, who were the first to show that, in the myxomatous degenerated valve, expected long-term durability would be the rule rather than the exception. Indeed, Carpentier has shown in his seminal work that the probability of valve failure at 12 years after repair of mitral regurgitation from this cause is less than $5 \%^{5}$; similar results have been reported by Duran and associates. ${ }^{6}$

Early in our experience, posterior leaflet repairs were performed with resection of the middle scallop with or without placement of an annuloplasty ring. As more experience has been gained, however, repair of the more complex lesions involving both anterior and posterior lesions have become commonplace. Like David and associates, ${ }^{12}$ who recently reported their experience, we reported that structural valve degeneration after repair occurred most often when an anterior leaflet resection was required or if an annuloplasty ring had not been placed. Yacoub and associates ${ }^{13}$ have emphasized that mitral valve repairs need not include annuloplasty rings. In many cases this is possible, although the anulus of the myxomatous degenerated valve, particularly one that is long standing, may be deformed to such a degree that the reshaping of the anulus by placement of the mattress sutures around the posterior anulus and then placement of the annuloplasty becomes important. The stabilization of the posterior anulus with a ring or some type of support has been considered important for the stabilization of the posterior leaflet and create a buttress against which the anterior leaflet can open and close. There exists continuing discussion about the ideal annuloplasty ring, either the rigid Carpentier-Edwards ring or the more flexible Duran ring. There is some evidence that the softer flexible ring is more beneficial to postoperative left ventricular performance. ${ }^{14}$ We have systematically used the more pliable and flexible Duran ring in our recent experience because of its better adaptability, although no differences in outcomes were noted between the two rings. We believe that the prevalence of systolic anterior motion of the mitral valve is less after the use of this device ${ }^{15}$ compared with the Carpentier-Edwards ring, ${ }^{16,17}$ unless, as Carpentier 
suggests, a sliding posterior valvuloplasty is carried out by annular preshortening (personal communication, 1989). A number of surgeons have now begun to use only posterior annular support: Denton Cooley (personal communication, 1992) and Delos Cosgrove (personal communication, 1993) believe that stabilization of the posterior anulus is the most critical factor in mitral valve repair.

Operative survival in this series included a large percentage of patients over 70 years of age, was $97.7 \%$. This is a "pure" series of mitral regurgitation without any other valve lesion, and this operative risk, particularly in a large group of patients with both coronary artery disease and a high percentage of patients over 70 years of age, compares favorably with other series of valve repairs and replacements. ${ }^{18}$ Much has been written about the differences in mitral valve repair and mitral valve replacement for mitral regurgitation, ${ }^{19-21}$ suggesting early and late results are far worse after replacement. We recently reported no difference in the operative mortality between mitral valve replacement and mitral valve repair when, with the former, we preserved the posterior leaflet and chordae papillary muscle continuity. ${ }^{22}$ Other current reports have also documented that operative survival is equal in repair and replacement. ${ }^{23}$ Preservation of all the papillary muscles and chordae with mitral valve repair are important for not only better immediate left ventricular function, but data suggests that improvement in late survival, as well as a reduction in thromboemboli, may be the result of improved postoperative cardiac function. Although very few studies have documented the improvements in function after repair and replacement leaving all the papillary muscles in place, David and $\mathrm{Ho}^{24}$ and Rozich and associates ${ }^{25}$ have shown that ejection fraction and other more sensitive indexes of left ventricular function were better preserved when the papillary muscles were left in continuity. However, it does appear that patients after mitral valve repair for mitral regurgitation seem to have a better long-term survival. ${ }^{26,27}$ One should be careful, however, in comparing long-term survival of nonmatched and nonprospectively randomized patients, but the data suggest that survival and function are better because of the preservation of papillary muscles and chordae. In cases of chronic mitral regurgitation, preservation of this anatomic relationship appears to be more important than closure of the "pop-off" valve for the left ventricle previously thought to be the more important focus of the repair. ${ }^{28}$

The prevalence of thromboembolism has been exceedingly low after mitral valve repair, even though at least one third of our patients are in chronic atrial fibrillation during anticoagulation therapy, a finding documented by others. ${ }^{19-21}$ The minimal presence of prosthetic material and better hemodynamics with the repaired valve are obvious advantages over mitral valve replacement. David and associates ${ }^{12}$ in a recent paper reported a higher prevalence of thromboemboli despite an intense perioperative anticoagulation regimen. These results may reflect the fact that this was not a pure series of patients with mitral regurgitation, but included other valve operations.

In summary, mitral valve repair for mitral regurgitation as a result of myxomatous degeneration of the mitral valve is feasible in a large percentage of patients and is associated with a low mortality and morbidity. Late results indicate that there is excellent survival, and a low prevalence of thromboembolic and infectious complications. Structural valve degeneration remains the major form of morbidity after this operation, but as experience with these procedures increases, the prevalence of structural valve degeneration decreases. The study also confirms that some form of annuloplasty ring appears to be important in the overall mitral valve reconstructive process.

\section{REFEREN CES}

1. Marks AR, Choong CY, Sanfilippo AJ, Ferre M, Weyman AE. Identification of high-risk and low-risk subgroups of patients with mitral valve prolapse. N Engl J Med 1985; 320:1031-6.

2. Nishimura RA, McGoon MD, Shub C, et al. Echocardiographically documented mitral valve prolapse: long-term follow-up of 237 patients. N Engl J Med 1985;313:1305-9.

3. Wilcken DEL, Hickey AJ. Lifetime risk for patients with mitral valve prolapse of developing severe valve regurgitation requiring surgery. Circulation 1988;78:10-14.

4. Olson LJ, Subramanian R, Ackerman DM, Orszulak TA, Edwards WD. Surgical pathology of the mitral valve: a study of 712 cases spanning 21 years. Mayo Clin Proc 1987;62:22-34.

5. Deloche A, Jebara VA, Relland JYM, et al. Valve repair with Carpentier techniques: the second decade. J THORAC CardiovasC Surg 1990;99:990-1002.

6. Duran CG, Revuelta JM, Gaite L, Alonso C, Fleitas MG. Stability of mitral reconstruction surgery at 10-12 years for predominantly rheumatic valvular disease. Circulation 1988;78(Suppl):191-6.

7. Cohn LH, DiSesa VJ, Couper GS, et al. Mitral valve repair for myxomatous degeneration and prolapse of the mitral valve. J Thorac Cardiovasc Surg 1989;98:987-93.

8. Frater RWM, Vetter HO, Zussa C, Dahm M. Chordal replacement in mitral valve repair. Circulation 1990; 82(Suppl):IV125-30.

9. El Asmar B, Acker M, Couetil JP, et al. Mitral valve repair in the extensively calcified mitral valve annulus. Ann Thorac Surg 1991;52:66-9. 
10. Cox DR. Regression models and life tables. J R Stat Soc (B) $1972 ; 34: 187-220$.

11. Cosgrove DM, Stewart WJ. Mitral valvuloplasty. Curr Probl Cardiol 1989;14:355-415.

12. David TE, Armstrong S, Sun Z, Daniel L. Late results of mitral valve repair for mitral regurgitation due to degenerative disease. Ann Thorac Surg 1993;56:7-12.

13. Yacoub M, Halim M, Radley-Smith R, et al. Surgical treatment of mitral regurgitation caused by floppy valves: repair versus replacement. Circulation 1981;64(Suppl): II210-6.

14. David TE, Komeda M, Pollick C, Burns RJ. Mitral valve annuloplasty: the effect of the type on left ventricular function. Ann Thorac Surg 1989;47:524-28.

15. Kenny J, Cohn LH, Shemin R, Collins JJ Jr, Plappert M, St. John Sutton MG. Doppler echocardiographic evaluation of ring mitral valvuloplasty for pure mitral regurgitation. Am J Cardiol 1987;59:341-5.

16. Grossi EA, Galloway AC, Parish MA, et al. Experience with twenty-eight cases of systolic anterior motion after mitral valve reconstruction by the Carpentier technique. $\mathrm{J}$ Thorac Cardiovasc Surg 1992;103:466-70.

17. Mihaileanu S, Marino JP, Chauvaud S, et al. Left ventricular outflow obstruction after mitral valve repair (Carpentier's technique): proposed mechanisms of disease. Circulation 1988;78(Suppl):I78-84.

18. Scott ML, Stowe CL, Nunnally LC, et al. Mitral valve reconstruction in the elderly population. Ann Thorac Surg 1989;48:213-7.

19. Angell WW, Oury JH, Shah P. A comparison of replacement and reconstruction in patients with mitral regurgitation. J THORAC CaRdiovasC SuRg 1987;93:665-74.

20. Galloway AC, Colvin SB, Baumann FG, et al. A comparison of mitral valve reconstruction with mitral valve replacement: intermediate-term results. Ann Thorac Surg 1989; 47:655-62.

21. Perier P, Deloche A, Chauvaud S, et al. Comparative evaluation of mitral valve repair and replacement with Starr, Bjork, and porcine valve prostheses. Circulation 1984; 70(Suppl):I187-92.

22. Cohn LH, Couper GS, Kinchla NM, Collins JJ. Decreased operative risk of surgical treatment of mitral regurgitation with or without coronary artery disease. J Am Coll Cardiol 1990;16:1575-78.

23. Craver JM, Cohen C, Weintraub WL. Case-matched comparison of mitral valve replacement and repair. Ann Thorac Surg 1990;49:964-9.

24. David TE, Ho WC. The effect of preservation of chordae tendineae on mitral valve replacement for postinfarction mitral regurgitation. Circulation 1986;74(Suppl):I116-20.

25. Rozich JD, Carabello BA, Usher BW, Kratz JM, Bell AE, Zile MR. Mitral valve replacement with and without chordal preservation in patients with chronic mitral regurgitation: mechanisms for differences in postoperative ejection performance. Circulation 1992;86:1718-26.

26. Rankin JS, Feneley MP, St. J. Hickey M, et al. A clinical comparison of mitral valve repair versus valve replacement in ischemic mitral regurgitation. J THORAC CARDIOvaSC SURG 1988;95:165-77.

27. Sand ME, Naftel DC, Blackstone EH, Kirklin JW, Karp RB. A comparison of repair and replacement for mitral valve incompetence. J THORAC CARDIOVASC SURG 1987; 94:208-19.

28. Kirklin JW. Replacement of the mitral valve for mitral incompetence. Surgery 1972;72:827-36.

\section{Discussion}

Dr. Lawrence I. Bonchek (Lancaster, Pa.). I would like to comment on structural deterioration in flexible rings versus that in rigid rings. It appeared from your abstract that deterioration occurred more often in patients who had received rigid rings than it did in those who had received flexible rings.

In our own experience with mitral valve repair, which is now approximately 200 cases, we found the opposite to be true regarding recurrences. We have put in only about a half dozen flexible rings and have had two recurrences in those patients. I believe the results depend on what one is most familiar with and most comfortable with; I noted that in your series you used the flexible ring more often, and I suspect you were better with it.

Because there are so many different methods of repairing mitral valves successfully, any surgeon who is comfortable with a rigid ring or with a flexible ring ought not be too easily swayed and ought to continue using what works for him or her.

Dr. James H. Oury (Missoula, Mont.) Our own series, another American series, substantiates your findings. This series covers 1980 to 1992 , with a total of 221 patients undergoing repair. This series is heavily weighted toward either ischemic or, as in the case of your report, degenerative disease, which accounted for 98 cases ( $45 \%$ ) of the overall series; a small number of cases of rheumatic disease. One death occurred in this group, and we performed seven reoperations, which are an inherent part of any series of mitral valve repair. The average patient age was 67 years, with a range of 21 to 85 years, which lends some credence to using a ring annuloplasty of some type as a reinforcement for these repairs. We deal with an older age group in the United States, and I think that is an important point.

Our first patient underwent operation in 1974; postoperative systolic angiography showed no mitral regurgitation in the patient, who had undergone annuloplasty with a CarpentierEdwards ring (Baxter).

This patient was alive and doing very well 19 years after her mitral valve repair. Since 1976, we have used the flexible ring exclusively. We have had no occurrence of systolic anterior motion with this particular ring that we have identified. I would ask you to comment on the prevalence of systolic anterior motion in your series and if you think there is any difference between the flexible and the rigid ring in that regard.

Dr. Cohn. I think the great contribution in this area, thanks to Alain Carpentier and Carlos Duran, is the concept of a ring annuloplasty. Until that was done, there was really no standardized approach to these operations. After these rings were introduced, the whole concept of mitral repair, which has become an exceedingly complex series of operations, was built on that sort of framework. When you have a standardized way to do things, it is extraordinarily helpful. 
I have no particular quarrel with Dr. Bonchek in regard to what type of ring is used. I think one does what works best in one's own clinic, and, therefore, we have used Duran rings in a large number of cases. We do believe, for us at least, either a posterior leaflet type of stabilization or some form of annuloplasty ring is helpful.

The problem of recurrence is one that I do not think you can predict. We have had recurrences in patients with a small anulus, where the tissue has been relatively friable, but we have had most recurrences when we did not use a ring, where the anulus was distorted and needed to be reshaped by the ring, which I think is important. Now, I do not know how to predict recurrence, but I find that ring annuloplasty is much more predictable, particularly if you are helping residents and fellows to learn these techniques, to use this methodology.

Again, to Dr. Bonchek, we analyzed our statistics and added 20 cases to the numbers, and no statistical difference was found between either type of ring with regard to structural valve degeneration.

To Dr. Oury, in all of these patients, by having a postoperative echocardiogram before they were discharged from the hospital, we did not observe a single case of systolic anterior motion. 